\title{
SEQUESTRATION OF THE LUNG
}

\author{
BY \\ MARY C. BUCHANAN \\ From the Queen Elizabeth Hospital for Children, London
}

(RECEIVED FOR PUBLICATION SEPTEMBER 15, 1958)

The condition of an abnormal pulmonary artery supplying a sequestrated segment is not well known although more than 30 cases have been described. The fact that these cases have come from a few centres (Pryce, 1946; Pryce, Sellors and Blair, 1947; Butler, 1947; Douglass, 1948; Bruwer, Claggett and McDonald, 1950; McDowell, Robb, Hinds and Nicks, 1951; Kergin, 1952; McDowell, Robb and Indyk, 1955) suggests that the condition may not be as rare as is believed. Once infected the sequestrated lobe is the cause of a chronic and disabling illness which can be completely cured by surgery and therefore merits attention.

Pryce (1946) and Pryce, Holmes Sellors and Blair (1947) fully described the condition and were first to publish eight cases successfully treated by surgery. The condition consists of a large artery arising from the abdominal or thoracic aorta, and entering the lung in the region of the diaphragm to supply a sequestrated or dislocated portion of the lung. The tissue in this ectopic piece of lung consists of normal pulmonary elements, with bronchi which are not in continuity with the bronchi of the normal lung. In some cases there are infective changes present with associated bronchiectasis. In others the tissue is largely cystic. The abnormal artery may (1) supply normally connected lung, (2) supply the sequestrated mass and normal lung, and (3) supply only the mass. The artery is elastic and is a pulmonary artery. Because of its origin from the aorta the pressure in this vessel is higher than in a normal pulmonary artery and arteriosclerotic changes are not infrequent even when the normal pulmonary vessels show no such change. Infective changes in the tissue supplied may predispose toward this sclerosis. Apart from this abnormal artery the cardiovascular system is normal. The blood leaves the abnormal segment by the pulmonary veins.

In the articles by Pryce (1946) and Pryce et al. (1947) the development of the ectopic tissue is discussed: the abnormal vessel is the primary malformation and Pryce and his fellow workers suggest that sequestration is the result of traction exerted through the capillaries of the adventitious blood supply in the developing lung. In their opinion infection of the mass probably occurs by direct spread from a pneumonic process in the adjacent lung, perhaps occasionally from the blood stream. The persistence of infection, which sometimes proceeds to suppuration, appears to be due to lack of adequate bronchial drainage.

Cases usually present as recurrent pneumonia, empyema, cysts or bronchiectasis. The abnormal vessel, especially if arising from the abdominal aorta, may not be easily seen at operation, and, if unsuspected, fatal haemorrhage may result.

The present case is described as it shows some interesting features.

\section{Case History}

Joyce W., aged 8 years 3 months, attended the Queen Elizabeth Hospital, London, in January, 1952, with vague symptoms of ill health. She tired readily and had occasional headaches and pains in the limbs. She had had a cough for two weeks. Clinically there was no abnormality. A Mantoux 1:1,000 tuberculin test was negative and her E.S.R. was $7 \mathrm{~mm}$./hour. A chest radiograph then taken showed no evidence of a pulmonary lesion except basal emphysema on both sides. After six weeks' convalescence she was better in every way.

She remained well for about two years. Then she was admitted to the Queen Elizabeth Hospital, London, in November, 1955, aged 11 years 1 month. The history obtained was similar to that of the previous episode. She had been unwell for two weeks. For seven days headaches were severe and she was giddy on taking exercise. She had one epistaxis. For two weeks she had had a hard, dry cough. On admission she was a sallow, tired-looking girl, but cheerful. Her temperature was $103^{\circ} \mathrm{F}$. Respiratory rate varied between 20/25 per minute. Movement of the right base was slightly diminished and the vocal resonance was decreased. There were a few rales at both bases. Mantoux $1: 1,000$ was repeatedly negative. The blood showed a polymorph leucocytosis in the region of 18,000 total W.B.C. with $85 \%$ segmented cells. The haemoglobin was $90 \%$ $(13.46 \mathrm{~g} . \%)$. On admission a radiograph of the chest 
showed a partial collapse of the right middle lobe and the anterior segment of the lower lobe. Dr. Hodson suggested that there 'might be underlying changes' (Fig. 1).

Treatment with full doses of sulphadimidine was ineffective in controlling the symptoms and pyrexia. After three days penicillin was added with no effect. Two days later this treatment was discontinued and she was treated with aureomycin. She began to feel much better and the pyrexia settled in two weeks from admission. During this time she had pyrexial episodes, with return of headache lasting from three to four days. Serial radiographs showed some resolution of the lesion at the right base, but there was a considerable degree of residual damage. A tomogram on December 20, 1954, showed cyst-like cavitation in the periphery of the right lower lobe, irregular consolidation and bronchial wall thickening.

After 13 weeks in hospital the cough had cleared and the E.S.R. had been normal for two weeks. There was still diminished movement and decreased vocal resonance over the right lower zone, but no adventitious sound. She was discharged home to be admitted for a bronchogram about one month later if the lesion persisted.

Three weeks later in March, 1955, she was re-admitted with anorexia and recurrence of cough. The physical findings were as on discharge. She had a moderate pyrexia $\left(100^{\circ}\right.$ F. $)$. The E.S.R. was raised and there was a polymorph leucocytosis. On this occasion treatment with sulphadimidine was successful in contrclling the symptoms. Two weeks later she was apyrexial and her blood tests were normal in all respects. A bronchogram was done and Dr. Hodson reported 'all the major segments were identified in the left lower lobe. The diseased area lies medial to the lower lobe behind the heart and causes a spreading out and arching of the right lower bronchi round it. It itself seems to have no communication with the bronchial tree. The whole behaviour, site and appearance of this lesion suggests sequestrated lung segment' (Figs. 2 and 3).

Excision of the right lower lobe was performed by
Mr. Holmes Sellors on May 16, 1956. The lung was free except for a few recent adhesions between the lower lobe and the diaphragm. There was a small mass in the posterior basal segments. Entering this mass from the region of the diaphragm was a vessel about $3 \mathrm{~mm}$. in diameter. Dissection lobectomy was quite straightforward.

The size of the right lower lobe was 9 by 11 by $8 \mathrm{~cm}$.

ON SECTION. In the posterior subapical area there was a small abscess cavity about $0.5 \mathrm{~cm}$. in diameter. In the posterior basal region there was an area of lipoid pneumonitis containing what appeared to be a number of small abscesses. In the antero-medial portion of the lobe there was a tube-like structure which extended laterally and divided into a number of branches. This was thought to be an ectopic bronchus. There was emphysema of the basal segments.

Histology. The abscess in the posterior subapical area was lined by fibrous tissue, with a single layer of low cuboidal epithelium in places. This could have originally been a bronchiectatic cyst. In the posterior basal area the small abscesses were destroyed small bronchi. There was also a larger bronchiectatic cavity with ulceration of its surface, and loss of its ciliated epithelium. This was surrounded by areas of chronic pneumonitis with the alveoli filled in places with lipoid phagocytes. Many of the ulcerated bronchi were filled with pus. The 'pipelike' structure proved to be a thin-walled ectopic bronchus with rudimentary cartilage. The wall contained no glands or muscle. Laterally, the wall was broken up by abscess fragmentation, the abscess perforating into an adjacent small bronchus.

After operation the patient was very well. Her appetite was excellent and she had plenty of energy: "quite a different child; has never been known to be so lively.' Previously she had been easily irritated and easily tired.

\section{Discussion}

The main interest in the case described above is the apparently normal chest radiography taken two

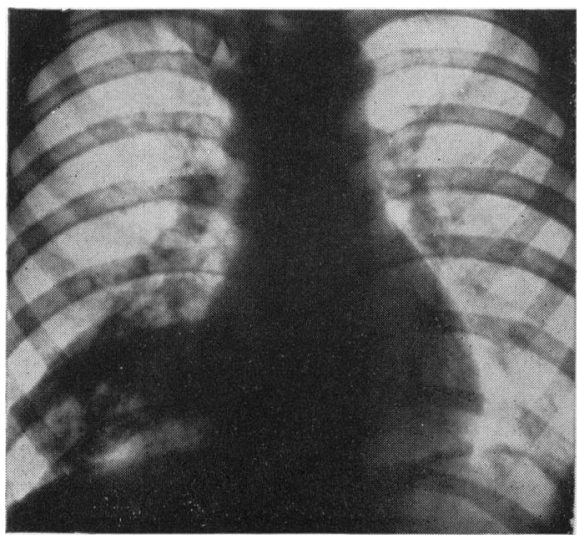

FIG. 1.-Joyce W. Partial collapse of right middle lobe and anterior segment of lower lobe.

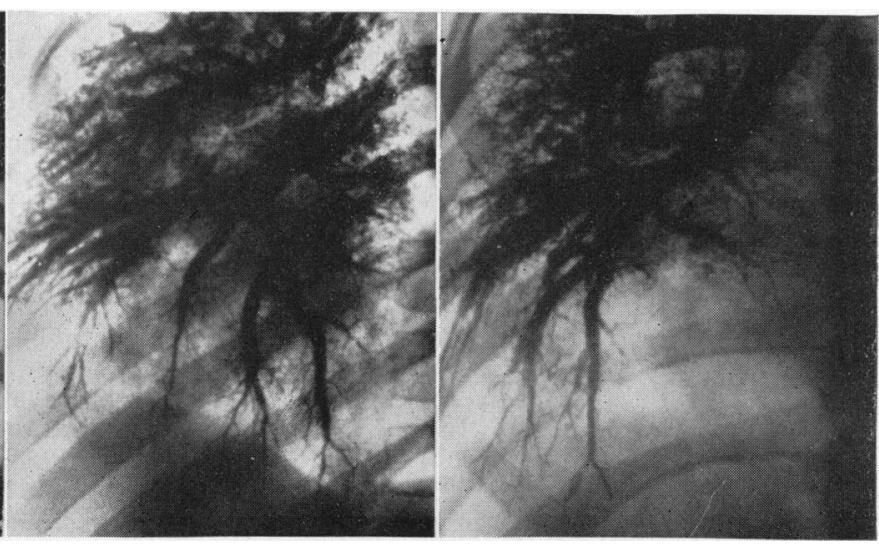

FIGS. 2 and 3.-Spreading out and arching of right lower bronchi and diseased area. 
years before the series of illnesses which culminated in lobectomy. There appear to be three explanations for this: (1) The sequestrated segment was unaerated and uninfected and in this state occupied such a small volume that it cast no shadow on the radiograph. (2) The segment contained air but was without infective changes and disturbed the normal pulmonary markings so little that again it cast no peculiar shadow. (3) Sequestration of the segment occurred in the following two years, i.e. was postnatal.

Against (1) is the unlikelihood that even a small collapsed segment in this region would fail to produce some kind of irregularity in a good quality film.

Against (3) is the rudimentary structure of the ectopic bronchial tissue found in the abnormal segment after excision. Were this bronchus amputated well after birth it would be likely to retain a more or less normal structure.

The second explanation seems the most likely: that there was a small communication between the air contained in the surrounding normal lung and the air spaces in the ectopic tissue, which was sufficient to aerate the latter, but which was insufficient to drain the products of infection once the latter had occurred.

\section{Summary}

The syndrome of sequestrated lung segment is probably not as rare as is generally believed. The condition is disabling. It is cured by operation. There are few symptoms referable to the lungs, minimal physical signs but gross radiological changes. The condition once suspected can be diagnosed before operation. The anatomical lesion is again described and the presence of an abnormal vessel from the abdominal aorta is foreseen. Comment is made on the probable aetiology of the condition.

I wish to thank Dr. C. T. Potter for his permission to publish an account of this case; also Dr. C. J. Hodson for the radiographic prints and for helpful criticism.

\section{REFERENCES}

Bruwer, A., Claggett, O. T. and McDonald, J. R. (1950). J. Thorac Surg., 19, 957 .

Butler, E. F. (1947). Ibid., 16, 199.

Douglass, R. (1948). Ibid., 17, 712

Kergin, F. G. (1952). Ibid., 23, 55.

McDowell, C., Robb, D. and Indyk, J. S. (1955). Thorax, 10, 73. Minds, W. R. and Nicks. R (1951) Brit. J. Surg., 39, 87 Pryce, D. M. (1946). J. Path. Bact., 58, 457. Pryce, Sellors, T. Holmes and Blair, L. G. (1947). Brit. J. Surg.,
35, 18. 